\title{
Plasma hemoglobin in COVID-19: authors' reply
}

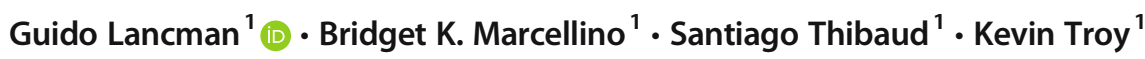

Received: 19 October 2020 / Accepted: 2 November 2020 / Published online: 6 November 2020

(C) Springer-Verlag GmbH Germany, part of Springer Nature 2020

\section{Dear Editor,}

Tiwari et al. raise several important points regarding interpretation of free plasma hemoglobin (plasma-Hb) results in our letter. Although renal replacement therapy (RRT) can raise the level of plasma- $\mathrm{Hb}$, we found no statistically significant difference between patients who were receiving RRT and those who were not (mean $13.4 \mathrm{mg} / \mathrm{dL}$ [SD 14.0] for RRT vs mean 21.4 $\mathrm{mg} / \mathrm{dL}$ [SD 18.4] for no RRT, $p=0.16$ ). Of the 9 patients with plasma- $\mathrm{Hb}>30 \mathrm{mg} / \mathrm{dL}$, only 2 were on RRT, making RRT an unlikely explanation for elevated plasma-Hb in our study.

Of the 10 patients with minimal schistocytosis, 4 were in the highest plasma-Hb group ( $>30 \mathrm{mg} / \mathrm{dL}$ ) which may reflect a higher level of microvascular endothelial damage; however, this is difficult to interpret as the degree of schistocytosis was very mild. Furthermore, of the 3 patients who had ADAMTS13 activity checked as part of the workup for thrombocytopenia, 1 was found to have heparin-induced thrombocytopenia, 1 had clear laboratory evidence of disseminated intravascular coagulation (elevated PT/PTT and D-dimer, low fibrinogen and haptoglobin), and 1 had likely bone marrow suppression from superimposed bacterial sepsis, with the peripheral smear not concerning for a thrombotic microangiopathy.
With regard to the test itself, the plasma-Hb level was analyzed by spectrophotometry, which can be falsely positive in the setting of bilirubin $>5 \mathrm{mg} / \mathrm{dL}$. However, only two patients had bilirubin in this range $(7.9 \mathrm{mg} / \mathrm{dL}$ and $5.4 \mathrm{mg} / \mathrm{dL}$, with plasma$\mathrm{Hb} 10.9 \mathrm{mg} / \mathrm{dL}$ and $77.7 \mathrm{mg} / \mathrm{dL}$, respectively), and thus, this is unlikely to have been a major confounder in our study.

At this time, the cause of the elevations in plasma-Hb in our patients remains unexplained by common confounders. We look forward to other independent studies on plasma- $\mathrm{Hb}$ levels in severe COVID-19 to see if these findings are replicated elsewhere.

\section{Compliance with ethical standards}

Conflict of interest The authors declare that they have no conflict of interest.

Ethical approval This study was approved by the Institutional Review Board at the Icahn School of Medicine at Mount Sinai. Waiver of informed consent was obtained for this retrospective study.

Publisher's note Springer Nature remains neutral with regard to jurisdictional claims in published maps and institutional affiliations.

Guido Lancman

guido.lancman@mssm.edu

1 Division of Hematology and Medical Oncology, Icahn School of Medicine at Mount Sinai, ANN 24-61, 1468 Madison Ave, New York, NY 10029, USA 